\title{
Detection of the Causative Bacterium of Vibriosis in Kuruma Prawn, Penaeus japonicus
}

\author{
Leobert D. de la Pen̄a*1, Kazuo Momoyama*2, Toshihiro Nakai*1, \\ and Kiyokuni Muroga ${ }^{* 1,3}$ \\ ${ }^{*}$ Faculty of Applied Biological Science, Hiroshima University, \\ Higashi-Hiroshima 724, Japan \\ *2 Yamaguchi Prefectural Naikai Fisheries Experiment Station, \\ Yamaguchi 754, Japan
}

(Received August 5, 1992)

\begin{abstract}
A one-year field survey on the presence of Vibrio sp. PJ, the causative agent of vibriosis in kuruma prawn (Penaeus japonicus), was carried out in prawn farms in Hiroshima and Yamaguchi Prefectures by a conventional bacterial culture method. The result revealed that the pathogen has already been widely distributed in the prawn culture environment. The population of the pathogen increased both in prawns and in their environment with a rise in water temperature.

Indirect fluorescent antibody technique (IFAT) was applied to smear specimens of the lymphoid organ of both experimentally and naturally infected kuruma prawns. This method was found effective as a rapid and reliable diagnostic method for the present disease, though the sensitivity was slightly lower than that of the culture method.
\end{abstract}

Vibriosis caused by a member of the genus Vibrio is considered to be the most important disease problem in the culture industry of kuruma prawn (Penaeus japonicus) in Japan because of considerable losses. Outbreaks of the disease in cultured kuruma prawn have been recorded since 1980, and studies on the characteristics of the causative bacterium (Vibrio sp.), histopathology, experimental treatment, and prophylactic vaccination have been done (Takahashi et al., 1985a, b; Egusa et al., 1988; Itami et al., 1989). Recently, the pathogen (Vibrio sp. PJ) was found to be composed of antigenically homologous strains and widely distributed in prawn farms in Japan (de la Peña, Tamaki, Momoyama, Nakai and Muroga, unpublished data). The diseased prawns are usually treated with medicated (oxytetracycline and oxolinic acid) pellet-type feeds, however, the disease has not been completely controlled and is still the biggest problem for prawn farmers.

To establish control measures for the disease, either avoidance of the exposure to the pathogen, vaccination, medication, or environmental man-

\footnotetext{
*3 To whom correspondence should be addressed.
}

ipulation for reducing disease triggering factors, ecological studies on the pathogen seem to be essential. In the present study, a one-year field survey was conducted to detect the pathogen from kuruma prawns and their environment by a conventional bacterial culture method.

Immunological procedures using antibodies labeled with fluorescent dyes or enzymes have been used extensively in the rapid diagnosis of infectious diseases and detection of many fish pathogens (Schill et al., 1989). In this study, indirect fluorescent antibody technique (IFAT) was evaluated for the rapid diagnosis of the disease.

\section{Materials and Methods}

\section{Field Survey by Culture Method}

Sampling sites: Monthly samplings were done in 4 ponds of 3 kuruma prawn farms at Osaki Kamijima (Ponds A and B), Hiroshima Prefecture and Aio-cho (Pond C) and Ube City (Pond D), Yamaguchi Prefecture from May to December 1990 (except Pond C in May). In each pond, 4 corners and 1 center were covered 
for sampling of surface water and bottom mud and/or sand (hereafter simply mud).

Collection of samples: The water samples were collected in sterile flasks. Three 10 -fold serial dilutions were made with sterile saline and 0.1 $\mathrm{m} l$ of each were plated onto ZoBell's 2216E agar and BTB-Teepole agar (Nissui) plates for bacterial examination. Mud samples were collected in individual sterile flasks using fine-mesh net. One gram of mud was homogenized in $10 \mathrm{~m} l$ sterile saline and three 10-fold serial dilutions were made. From each dilution, $0.1 \mathrm{~m} l$ were plated onto ZoBell's and BTB agar plates.

Five to ten apparently healthy prawns randomly caught from each pond were sacrificed at each sampling. Hemolymph, lymphoid organs, and gills were taken aseptically, then the former was streaked directly onto ZoBell's agar and the latter two were homogenized in sterile saline and plated onto the medium.

Microbiological examination: The plates inoculated with water/mud and prawn samples were incubated at $25^{\circ} \mathrm{C}$ for $48 \mathrm{~h}$. Vibrio sp. PJ-like colonies, if any, were selected for pure culture based on their morphological appearance, and submitted to slide agglutination test using anti-Vibrio sp. PJ (KH-1: a strain from Kagoshima Pref.) rabbit serum. The agglutinationpositive isolates were later confirmed to be Vibrio sp. PJ by biochemical characterization tests. Total viable cell count was also done on BTB and ZoBell's agar plates inoculated with water and mud samples obtained at Ponds A and B.

\section{Indirect Fluorescent Antibody Technique (IFAT)}

Bacteria: In addition to the strain KH-1, 8 strains of Vibrio sp. PJ (3 strains from Yamaguchi, 2 from Hiroshima, and each 1 from Oita, Ehime, and Kumamoto Prefs.) were used in this experiment. To test the cross reactivity with $\mathrm{KH}-1$ strain, strains of different Vibrio species and other fish pathogenic bacteria were used. These include Vibrio alginolyticus (V-447), V. campbelli (ATCC 25920T), V. parahaemolyticus (HO-5), $V$. harveyi (ATCC 14129T), V. anguillarum (PT-87050), V. ordalii (V-105), Aeromonas hydrophila (ET-4), A. salmonicida (ATCC 14174), Pseudomonas fluorescens (03L), Pasteurella piscicida (SJ 9102), and Edwardsiella tarda (NUF 82).

IFAT: IFAT was done according to the method of Chart et al. (1984) with some modifications. Duplicate smears of appropriate dilutions (ca. $10^{7} \mathrm{CFU} / \mathrm{ml}$ ) of each strain were made on nonfluorescent slides and introduced into IFAT. The smears were air-dried and fixed for $10 \mathrm{~min}$ in methanol, and again air-dried. They were overlaid with anti-KH-1 serum and incubated in a moist chamber at $37^{\circ} \mathrm{C}$ for $30 \mathrm{~min}$, then washed 5 times with PBS $(0.01 \mathrm{M}$ phosphate, $0.15 \mathrm{M} \mathrm{NaCl}, 0.02 \% \mathrm{NaN}_{3}, \mathrm{pH} 7.2$ ). Following air-drying, smears were overlaid with a commercially prepared fluorescein (FITC)-labeled goat anti-rabbit immunoglobulin (Kirkegaard and Perry Laboratories, Inc.) diluted to 1:100 then, incubated and washed as described above. Slides were air-dried and examined under a fluorescence microscope (Nikon EFD).

Preparation of experimentally infected prawns: Nine healthy prawns (mean weight, $14 \mathrm{~g}$ ) were intramuscularly injected with a $24 \mathrm{~h}$ culture of $\mathrm{KH}-1$ at a dose of $1.9 \times 10^{6} \mathrm{CFU} /$ animal. After 6,24 , and $36 \mathrm{~h}$, each 3 prawns were sacrificed and two unchallenged prawns were also sampled $(0 \mathrm{~h})$. The lymphoid organs and muscle of both infected and control prawns were taken aseptically and weighed then, homogenized in 9 volumes of sterile saline. Duplicate smears of homogenates were made on non-fluorescent slides for IFAT. In the case of hemolymph, samples $(30 \mu l)$ were directly placed onto the slides. The intensity of resultant fluorescence was graded into 3 ranks $(-,+,+)$. Viable cell count of $\mathrm{KH}-1$ strain in the tissues of the prawns was also made on ZoBell's agar.

Naturally infected prawns: Samplings were made in 1991 from August to October, when outbreaks of vibriosis were expected to occur. Thirty prawns were randomly collected from each of 2 private ponds ( $C$ and $D$ : the same ponds as those surveyed in the previous year). Lymphoid organs were removed aseptically, homogenized in $0.5 \mathrm{ml}$ of sterile saline, and smeared in duplicate on non-fluorescent slides. Presence of Vibrio sp. PJ in the homogenates was also determined by culture method on ZoBell's agar.

\section{Results}

\section{Field Survey}

During the field survey done from May to 


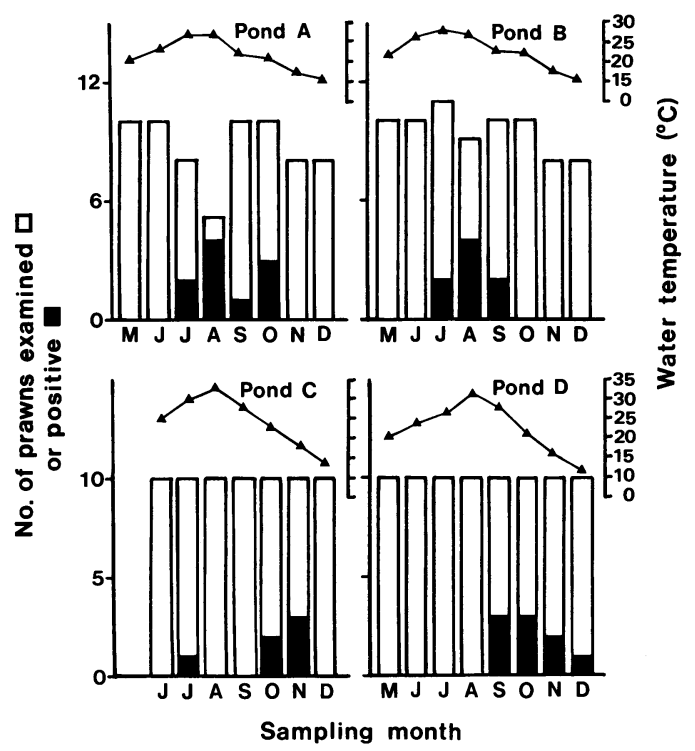

Fig. 1. Detection of Vibrio sp. PJ by culture method from kuruma prawns in farms in Hiroshima (Ponds A and B) and Yamaguchi (C and D) Prefectures in 1990.

December of 1990, Vibrio sp. PJ was detected from healthy prawns of the four ponds in summer and autumn (July to December). Probably owing to repeated medications, significant mortalities due to vibriosis were encountered only in Pond D. The appearance of the pathogen in prawns coincided with the peak and/or the following declining period of water temperature (Fig. 1).

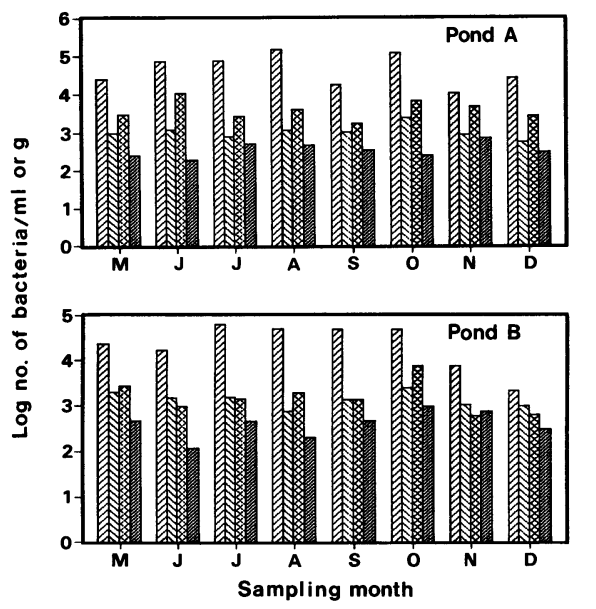

ZZoBell-Mud $\$$ ZoBell-Water BTB-Mud 2 BTB-Water

Fig. 2. Bacterial counts of pond water and mud in Ponds A and B on ZoBell's 2216E and BTB agar media.

The pathogen was also detected from rearing water from June to December except September and from mud in November, though only one out of five sites (4 corners and 1 center) was positive in each pond (Table 1). The pathogenicity of one isolate from water in June in Pond $\mathrm{C}$ was confirmed by injecting it into healthy prawns $\left(\mathrm{LD}_{50}: 1.7 \times 10^{1} \mathrm{CFU} / \mathrm{g}\right)$. In Fig. 2, the bacterial counts of pond water and mud from 2 ponds (A and B) on ZoBell's and BTB agar media are shown. Apparent seasonal changes in bacterial counts of water and mud

Table 1. Detection of Vibrio sp. PJ by culture method from pond water and mud in farms in Hiroshima and Yamaguchi Prefectures in 1990

\begin{tabular}{cccccccccc}
\hline \multirow{2}{*}{ Sample } & \multicolumn{7}{c}{ Sampling date (Month) } \\
\cline { 2 - 8 } & May & Jun. & Jul. & Aug. & Sept. & Oct. & Nov. & Dec. \\
\hline Rearing water & & & & & & & & & \\
Pond A & $0^{a}$ & 0 & 0 & 0 & 0 & 0 & 1 & 0 \\
Pond B & 0 & 0 & 0 & 1 & 0 & 1 & 0 & 1 \\
Pond C & 0 & 1 & 0 & 0 & 0 & 1 & 0 & 0 \\
Pond D & 0 & 0 & 1 & 0 & 0 & 1 & 1 & 1 \\
Mud/Sand & & & & & & & & \\
Pond A & 0 & 0 & 0 & 0 & 0 & 0 & 0 & 0 \\
Pond B & 0 & 0 & 0 & 0 & 0 & 0 & 0 & 0 \\
Pond C & - & 0 & 0 & 0 & 0 & 0 & 0 & 0 \\
Pond D & 0 & 0 & 0 & 0 & 0 & 0 & 1 & 0 \\
\hline
\end{tabular}

a Number of sites positive for Vibrio sp. PJ among 5 sites examined (4 corners and 1 center). 
were not observed during the research period from May to December.

\section{IFAT}

Nine selected strains of Vibrio sp. PJ including homologous $\mathrm{KH}-1$ were all positive for IFAT test with smear specimens using anti-KH-1 serum which was diluted $1: 1000$. The sensitivity threshold of the assay was at about $3 \times 10^{1} \mathrm{CFU}$ $\left(30 \mu l\right.$ of $\left.1 \times 10^{3} \mathrm{CFU} / \mathrm{ml}\right)$ of the homologous strain.

The specificity of IFAT using anti-KH-1 serum

Table 2. Specificity of indirect fluorescent antibody technique (IFAT) to some selected bacterial species at different dilutions of anti-Vibrio sp. PJ (KH-1) serum

\begin{tabular}{lccccc}
\hline \multicolumn{1}{c}{ Bacterium (strain) } & \multicolumn{5}{c}{ Fluorescence at serum dilution of 1: } \\
\cline { 2 - 5 } & 100 & 800 & 1000 & 1600 & 2000 \\
\hline Vibrio sp. PJ (KH-1) & + & + & + & + & - \\
Aeromonas hydrophila (ET-4) & - & - & - & & \\
Aeromonas salmonicida (ATCC 14174) & - & - & - & & \\
Pseudomonas fluorescens (03L) & - & - & - & - \\
Pasteurella piscicida (SJ 9102) & - & - & - & - \\
Edwardsiella tarda (NUF 82) & - & - & - & - \\
Vibrio alginolyticus (V-447) & + & $+^{*}$ & - & - \\
Vibrio campbelli (ATCC 25920T) & + & $+^{*}$ & - & - \\
Vibrio parahaemolyticus (HO-5) & + & $+^{*}$ & - & - \\
Vibrio harveyi (ATCC 14129T) & + & $+^{*}$ & - & - \\
Vibrio anguillarum (PT-87050) & + & $+^{*}$ & - & - \\
Vibrio ordalii (V-105) & + & $+^{*}$ & - & - \\
\hline
\end{tabular}

* Weak fluorescence.

Table 3. Detection of Vibrio sp. PJ (KH-1) in experimentally infected kuruma prawns using culture method and IFAT

\begin{tabular}{ccccc}
\hline \multirow{2}{*}{$\begin{array}{c}\text { Hours after } \\
\text { injection }\end{array}$} & \multirow{2}{*}{$\begin{array}{c}\text { Number of } \\
\text { prawns }\end{array}$} & \multicolumn{2}{c}{ Number of cells isolated $(\mathrm{CFU} / \mathrm{m} l$ or g)/result of IFAT } \\
\cline { 3 - 5 } & 2 & Hemolymph & Lymphoid organ & Muscle \\
\hline 0 & 3 & $0 /-$ & $0 /-$ & $0 /-$ \\
6 & 3 & $5.6 \times 10^{4} /+$ & $9.7 \times 10^{5} /+$ & $7.1 \times 10^{3} /+$ \\
24 & 3 & $1.1 \times 10^{5} / \mathrm{H}$ & $5.8 \times 10^{8} / \mathrm{H}$ & $4.5 \times 10^{4} / \mathrm{H}$ \\
36 & $4.3 \times 10^{5} / \mathrm{H}$ & $6.6 \times 10^{8} / \mathrm{H}$ & $1.4 \times 10^{8} / \mathrm{H}$ \\
\hline
\end{tabular}

Prawns (average weight, $14 \mathrm{~g})$ were intramuscularly injected with $\mathrm{KH}-1$ strain $\left(1.9 \times 10^{6} \mathrm{CFU} /\right.$ animal) and reared at $21^{\circ} \mathrm{C}$. Anti-KH-1 serum was used as first antibody at 1: 1000 .

Table 4. Detection of Vibrio sp. PJ by culture method and IFAT from lymphoid organs of kuruma prawns in 2 ponds in Yamaguchi Prefecture

\begin{tabular}{|c|c|c|c|c|}
\hline \multirow{2}{*}{ Sampling date } & \multirow{2}{*}{\multicolumn{2}{|c|}{$\begin{array}{l}\text { Pond and average } \\
\text { weight of prawn (g) }\end{array}$}} & \multicolumn{2}{|c|}{$\begin{array}{l}\text { Percentage of prawns positive for } \\
\text { Vibrio sp. PJ }\end{array}$} \\
\hline & & & Culture method & IFAT \\
\hline \multirow[t]{2}{*}{ Aug. 7} & $\mathrm{C}$ & 4.3 & $6.7(2 / 30)$ & $3.3(1 / 30)$ \\
\hline & $\mathrm{D}$ & 8.5 & $3.3(1 / 30)$ & $0 \quad(0 / 30)$ \\
\hline \multirow[t]{2}{*}{ Sept. } & $\mathrm{C}$ & 8.2 & $0 \quad(0 / 30)$ & $0 \quad(0 / 30)$ \\
\hline & D & 13.3 & $10.0(3 / 30)$ & $3.3(1 / 30)$ \\
\hline \multirow[t]{2}{*}{ Oct. 10} & $\mathrm{C}$ & 15.5 & $6.7(2 / 30)$ & $6.7(2 / 30)$ \\
\hline & D & 20.0 & $3.6(1 / 28)$ & $3.6(1 / 28)$ \\
\hline
\end{tabular}

IFAT first antibody: anti-KH-1 serum, diluted 1: 1000. 
was clearly demonstrated (Table 2). The Vibrio species tested gave a positive cross response at dilutions up to $1: 800$ but the specificity of the serum was revealed at $1: 1000$ dilution.

The results of the detection of Vibrio sp. PJ (KH-1) by IFAT and culture method in experimentally infected prawns are given in Table 3 . There was a good correlation between the isolation of KH-1 strain and the result of IFAT test. In this in vivo experiment, the sensitivity limit of the assay was almost the same as in in vitro test; $2 \times 10^{1} \mathrm{CFU}\left(30 \mu l\right.$ of $\left.7.1 \times 10^{2} \mathrm{CFU} / \mathrm{m} l\right)$.

The result of the three consecutive monthly samplings using culture method and IFAT in the 2 private ponds to detect Vibrio sp. PJ from naturally infected prawns was given in Table 4. Vibrio sp. PJ was detected by culture method from every group of specimens except for pond $\mathrm{C}$ at the second sampling, though detection rate was always low. Five out of 9 samples positive for culture method were also positive for IFAT test.

\section{Discussion}

From the one-year field survey on the presence of Vibrio sp. PJ in the prawn farms in Hiroshima and Yamaguchi Prefectures, the pathogen proved to be distributed in apparently healthy kuruma prawns and their culture environment. Based on this result and long survivability of the pathogen in sea water (de la Peña et al., unpublished data), it can be said that Vibrio sp. PJ has already been established in the prawn culture environment. The population of the pathogen increased both in prawns and their environment at the peak (Ponds $\mathrm{A}$ and $\mathrm{B}$ ) or the following declining period (Ponds C and D) of water temperature. These periods coincide with the season when deterioration of environmental conditions advances and vibriosis prevails in prawn farms. The deterioration seems to start at the middle of the culture period (July or August) judging from observations of the accumulation of organic wastes and hydrogen sulfide at the pond bottom. The time differences in occurrence of Vibrio sp. PJ between the two prefectures can be attributed partly to the difference in the time table of stocking. Ponds A and B (Hiroshima) were stocked earlier than Ponds C and D (Yamaguchi) by about two months thus, deterioration of environmental conditions in ponds in Yamaguchi Prefecture may have progressed later than in ponds in Hiroshima Prefecture. In mud, Vibrio sp. PJ was rarely detected probably because of the conditions unfavorable for the bacterium.

Some or most of the prawns positive for the detection of Vibrio sp. PJ (Fig. 1) were suspected to be at the initial stage of infection. In other words, the detection rate obtained here is thought to be lower than the true carrier rate, because we have often experienced that more than half of healthy appearing prawns purchased at these farms became ill with vibriosis during and after acclimation to laboratory conditions unless appropriate medications were done. This indicates that the carrier state of prawns will develop into overt infection through stress due to handling and adverse environmental conditions (Johnson, 1983). Dectection rate of Vibrio sp. PJ from carrier prawns will be enhanced by introducing a special method like enrichment pre-culture. Another method includes bacterial isolation after giving stress as done for the detection of Aeromonas salmonicida-carriers in salmonids (Bullock and Stuckey, 1975).

Since Vibrio sp. PJ has been established in prawn farms, it seems quite difficult to eradicate the pathogen from culture environment and chemotherapy appears to be a stopgap remedy. Thus vaccination and removal of stress factors are possible ways for the control of the disease. In order to minimize the damage due to vibriosis by modifying culture techniques or manipulating environmental conditions, we must determine the exact stress factors which actually predispose prawns to the acquisition of infection or produce overt infection in carriers.

Disease should be precisely diagnosed in the early stage of infection or even in carrier stage because correct diagnosis is the most critical step in disease control program (Baticados, 1988). Fluorescent antibody technique (FAT) has been described for several fish pathogens such as Edwardsiella tarda, Enterococcus seriolicida (Streptococcus sp.), Nocardia kampachi, Pasteurella piscicida, and Vibrio anguillarum (Schill et al., 1989). In the present study, all the tested strains of Vibrio sp. PJ exhibited positive reaction even at 1: 1000 dilution of anti- 
KH-1 serum in indirect fluorescent antibody technique (IFAT). This finding confirmed the earlier result of our study that there is a major O-antigen common to all the Vibriosp. PJ strains tested (de la Peña et al., unpublished data). Though the detection rate of the pathogen was slightly lower in IFAT than in culture method, IFAT was confirmed to be available for the diagnosis of this vibriosis because of its rapidity.

\section{Acknowledgements}

This work was supported by grants from the Fisheries Agency of Japan.

We thank Mr. T. Horie of Daiya-Yoshoku Co. Ltd., Mr. A. Aoki of Ube Prawn Farm, and Mr. Y. Matsumoto of Asahi Shoji Co., Ltd., for the sampling freedom, and to the Ministry of Education, Science and Culture of Japan (Monbusho) for the benevolent support to this work in the form of scholarship to the author (L. D. de la Peña).

\section{References}

Baticados, M. C. L. (1988): Typical prawn diseasescauses, prevention and treatment. In "Technical considerations for the management and operation of intensive prawn farms" (ed. by Y. N. Chiu, L. M. Santos and R. O. Juliano). U. P. Aquaculture Society, Iloilo City, Philippines, pp. 134-143.

Bullock, G. L. and H. M. Stuckey (1975): Aeromonas salmonicida: detection of asymptomatically infected trout. Prog. Fish-Cult., 37, 237-239.

Chart, H., D. H. Shaw, E. E. Ishiguro and T. J. Trust (1984): Structural and immunochemical homogeneity of Aeromonas salmonicida lipopolysaccharide. $J$. Bacteriol., 158, 16-22.

Egusa, S., Y. Takahashi, T. Itami and K. Momoyama (1988): Histopathology of vibriosis in kuruma prawn, Penaeus japonicus Bate. Fish Pathol., 23, 59-65.

Itami, T., Y. Takahashi and Y. Nakamura (1989): Efficacy of vaccination against vibriosis in cultured kuruma prawns Penaeus japonicus. J. Aquat. Anim. Health, 1, 238-242.

Johnson, P. T. (1983): Diseases caused by viruses, rickettsiae, bacteria, and fungi. In "The biology of crustacea. Vol. 6. Pathobiology" (ed. by A. J. Provenzano, Jr.). Academic Press, Inc., New York, pp. 1-78.

Schill, W. B., G. L. Bullock and D. P. Anderson (1989): Serology. In "Methods for the microbiological examination of fish and shellfish" (ed. by B. Austin and D. A. Austin). Eillis Horwood Limited, England, pp. 98-140.

Takahashi, Y., Y. Shimoyama and K. Momoyama (1985a): Pathogenicity and characteristics of Vibrio sp. isolated from cultured kuruma prawns Penaeus japonicus Bate. Bull. Japan. Soc. Sci. Fish., 51, 721730.

Takahashi, Y., T. Itami and A. Nakagawa (1985b): Therapeutic effects of oxytetracycline trial tablets against vibriosis in cultured kuruma prawns Penaeus japonicus Bate. Bull. Japan. Soc. Sci. Fish., 51, 16391643. 